\title{
Hydrological influences on long-term gas flow trends at locations in the Vogtland/NW Bohemian seismic region (German-Czech border)
}

\author{
Ulrich Koch and Jens Heinicke \\ Saxon Academy of Sciences (SAW) at Leipzig, Research Group Bad Brambach/Freiberg, Germany
}

\begin{abstract}
One of the typical methods for the identification of seismo-hydrological effects is to monitor changes in the free gas flow throughout springs or mofettes. For several years, the gas flow regime of mineral springs at Bad Brambach (Germany) and mofettes in the Nature Park Soos (Czech Republic) and its dependence on hydro-/meteorological parameters have been studied. The mineral spring 'Wettinquelle', Bad Brambach, is a well-known seismo-hydrologically sensitive location for swarmquakes at a special epicentral area of NW Bohemia. Since 2000, a slight upward trend in the gas flow of three Bad Brambach mineral springs has been observed, which became stronger after the 'Eisenquelle' spring capture reconstruction (winter 2003/2004). Similar behaviour could be detected at a mofette in Soos. The results correspond to a ${ }^{3} \mathrm{He} /{ }^{4} \mathrm{He}$ mantle ratio increase in gases at mofettes in the Cheb Basin $(\mathrm{CZ})$ traced by other authors for more than 12 years, and could give hints for a higher degassing activity of the magma body below that area. Common and special properties in the degassing regimes of the Bad Brambach and Soos locations are discussed. It is demonstrated that the long-term gas flow trend was interrupted in 2003 because of very low groundwater levels. This effect was amplified by the artificial groundwater lowering during the 'Eisenquelle' spring capture reconstruction.
\end{abstract}

Key words seismo-hydrology - gas flow - groundwater level - mineral springs - mofettes

\section{Introduction}

Knowledge on the effects of non-seismic influences plays an important role for the interpretation of fluid related anomalies (gas flow rate, $\mathrm{CO}_{2}$ and radon concentration) in connection with seismic events and for a reliable iden-

Mailing address: Dr. Ulrich Koch, Saxon Academy of Sciences (SAW) at Leipzig, Research Group Bad Brambach/Freiberg, Badstrasse 49, D-08648 Bad Brambach, Germany; e-mail: koch@saw-leipzig.de tification of seismo-tectonically induced processes.

Generally, the atmospheric pressure is supposed to be the most important parameter influencing the natural gas flux of springs and mofettes. In many studies, its behaviour is demonstrated and discussed in comparison to the gas flow rate (e.g., Pinault and Baubron, 1997; Heinicke and Koch, 2000; McGee et al., 2000; Rogie et al., 2001; Koch et al., 2003; Reddy et al., 2004). Normally, a positive air pressure gradient decreases the degassing rate from the ground, whereas suddenly occurring low-pressure areas may cause an anomaly-like increase in gas emission.

Very often, the published data series for seismo-hydrological interpretations are relatively short (some days to several weeks), and charac- 


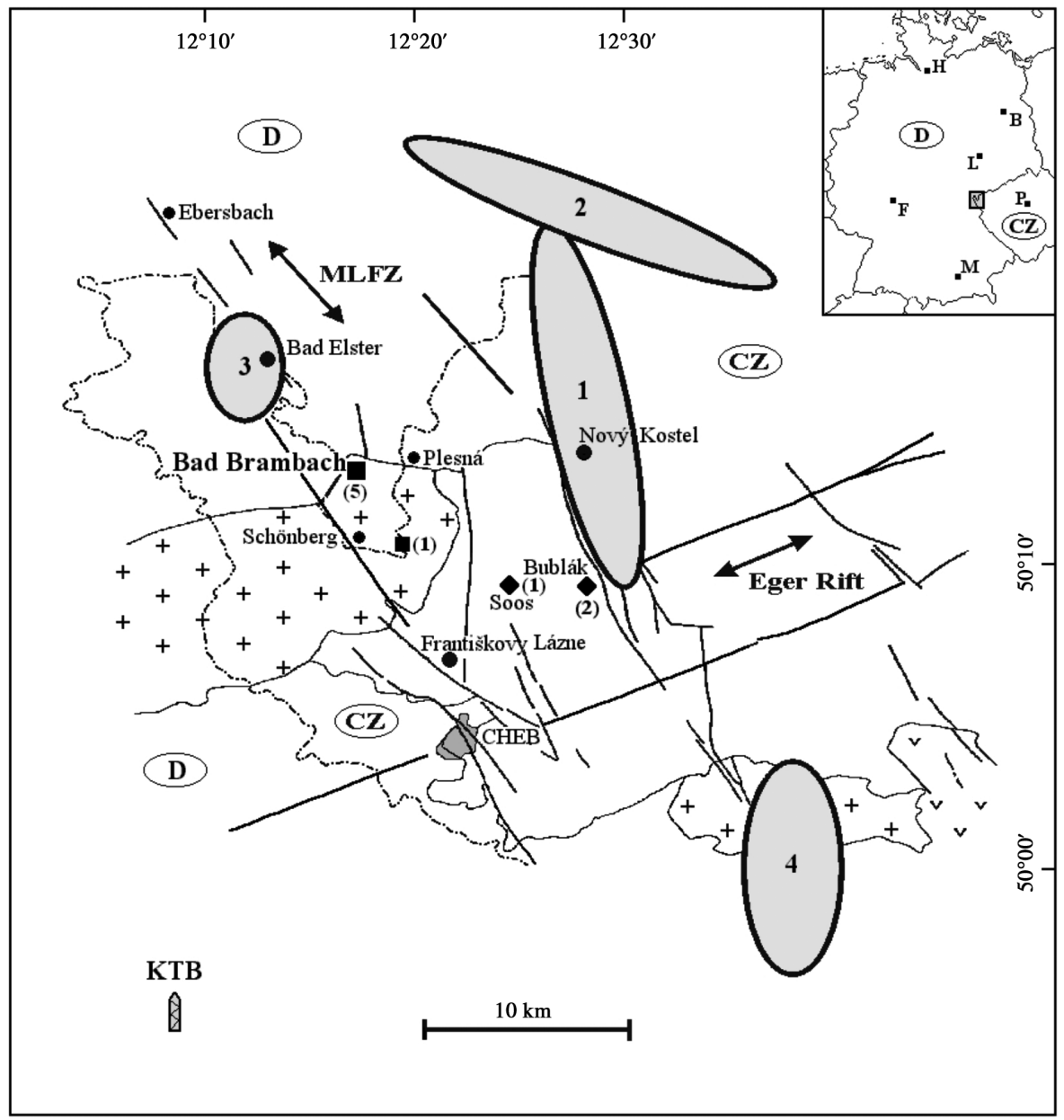

Fig. 1. Earthquake swarm region Vogtland/NW Bohemia with epicentral areas. For about 20 years, the highest earthquake frequency is observed within the epicentral area 1. Typical geological units: granite $(+)$, metamorphic rocks, sediments (white); main tectonic structures: Mariánské Lázně fault zone (MLFZ, NW-SE), Eger-Rift (ENE-WSW); $/$ springs/mofettes with the number of seismo-hydrological stations of the Saxon Academy (in parentheses); KTB: Continental Deep Drilling (Oberpfalz).

terised by spike-like flow anomalies. In that case, air pressure influences should be eliminated by means of statistical methods.

At present, long-term trends in gas emission are becoming more and more interesting in the context of seismo-hydrological investigations, for example, to obtain hints about the development of the degassing behaviour of a magmatic body, its possible volcanic activity and the inter- actions between the fluid regime and seismotectonic processes. The existence of such a magmatic body is also assumed below the Cheb Basin in NW Bohemia (Weinlich et al., 1999; Špičák and Horálek, 2001; Weise et al., 2001; Hainzl and Fischer, 2002; Bräuer et al., 2003).

Long-term trends may only be estimated if seasonal degassing variations can be recognised and separated reliably. Similarly to the air pres- 
sure, the hydrostatic pressure of the current groundwater level acts as a counter pressure on the degassing aquifer system affecting the flow rate of the ascending gases.

As a rule, variations in the groundwater level are seasonally conditioned with maxima after the snow melting in early spring and minima in late summer/early autumn.

\section{Locations and measurements}

For more than 15 years, fluid processes related to earthquakes have been investigated at the Vogtland/NW Bohemia swarmquake area (fig. 1). The region is characterised by many degassing mineral springs and mofettes where the ascending fluids are studied by hydrochemical, radiometric and isotope methods (Heinicke et al., 1995; Heinicke and Koch, 2000; Weise et al., 2001; Bräuer et al., 2003, 2005a,b, 2007; Koch et al., 2003).

The springs of Bad Brambach $\left(12.298^{\circ} \mathrm{E}\right.$, $50.239^{\circ} \mathrm{N}$ ) are characterised by a mineralisation of more than $2.5 \mathrm{~g} / \mathrm{l},{ }^{222} \mathrm{Rn}$ activities of $1.5-26$ $\mathrm{kBq} / \mathrm{l}$ and $\mathrm{CO}_{2}$ oversaturation ( $>2 \mathrm{~g} / \mathrm{l}$ dissolved $\mathrm{CO}_{2}$ ). The $\mathrm{CO}_{2}$ in most of the springs and in some dry gas outbursts (mofettes) of the region has a typical isotopic mantle signature, and is attributed to Tertiary and Quaternary volcanism as well as to neotectonic activities.

Numerous anomalous effects at the mineral spring 'Wettinquelle' and a gauge well in the

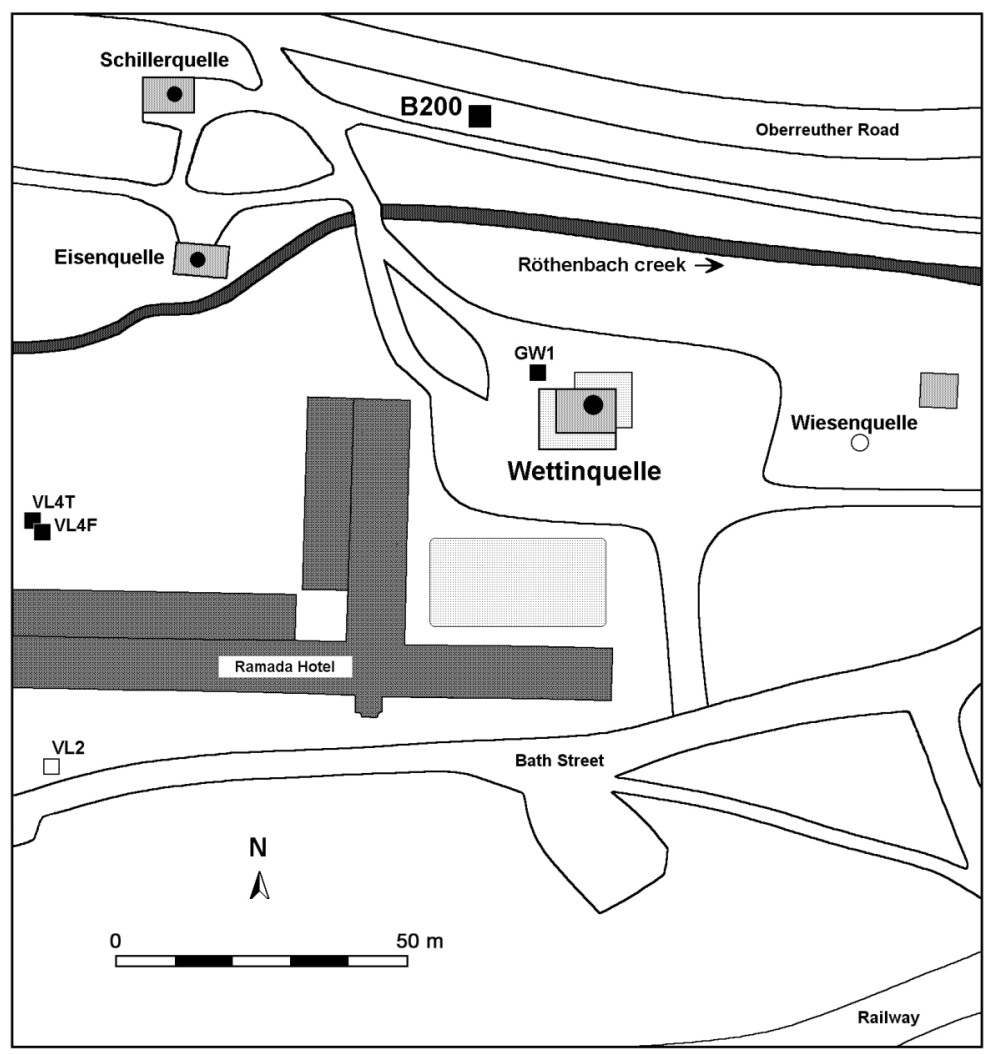

Fig. 2. Cure Park of Bad Brambach with seismo-hydrological measuring stations: $\bullet$ mineral springs with multiparameter and/or gas flow sensors; deep well (B200) and gauge wells (VL4T, VL4F, GW1) with water level sensors; $\mathrm{O} / \square$ other springs/gauge wells. 
Cure Park of Bad Brambach (precursors) as well as at two mofettes in Bublák and the Nature Park Soos, Czech Republic (co- and postseismic effects) have been observed and evaluated (Heinicke et al., 1995; Koch and Heinicke, 1996, 1999; Koch et al., 2003). The anomalies could be related mainly to changes in the pore pressure regime before seismic events in the vicinity of Nový Kostel (CZ), the most frequent epicentre of the seismicity in the region for more than 20 years (Horálek et al., 1996, 2000; Špičák and Horálek, 2001).

During the progression of the Bad Brambach studies in the last 10 years, the free gas flow throughout mineral springs proved to be the main parameter for a relatively clear identification of seismo-hydrological changes in the basement.

Reliable gas flow measurements have been accomplished at the mineral springs 'Eisenquelle' and 'Schillerquelle' since 1998. At the 'Wet- tinquelle', gas flow measurements have become possible only after the comprehensive capture reconstruction and the installation of a seismo-hydrological multiparameter station in 2000 (Koch et al., 2003; fig. 2, fig. 3). Continuous meteorological and groundwater level data of two gauge wells (VL4T: $15 \mathrm{~m}$ deep and GW1: $6 \mathrm{~m}$ deep) have been available since 1999 and 2000, respectively.

In summer 2000, seismically induced fluid effects were observed for the first time simultaneously at two different measuring locations of the Bad Brambach mineral spring area. The anomalies started with a spike-like pulse of the gas flow rate at the spring 'Wettinquelle', four weeks before the large swarmquake period in the autumn of 2000. Simultaneously, the water level increased about $25 \mathrm{~cm}$ recorded at the gauge well VL4T (fig. 2). This increase lasted up to the insert of the swarmquake series at the beginning of September 2000 (Koch et al., 2003).

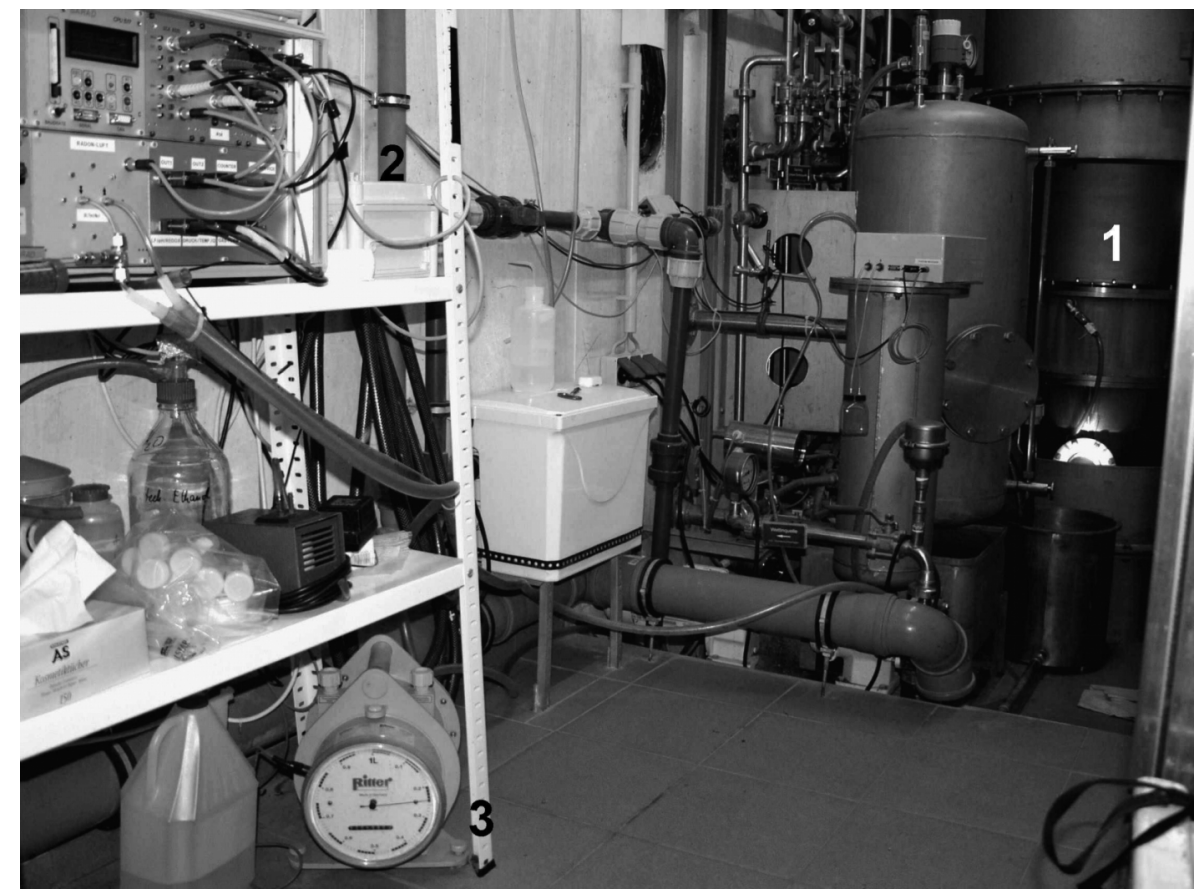

Fig. 3. 'Wettinquelle' spring basement with spring capture (1), multiparameter station (2) and gas flow counter (3); technical details: see Koch et al. (2003). 
The Nature Park Soos is located in the centre of the large West Bohemian gas emission zone, $8 \mathrm{~km} \mathrm{SSW}$ of Nový Kostel. It is a natural

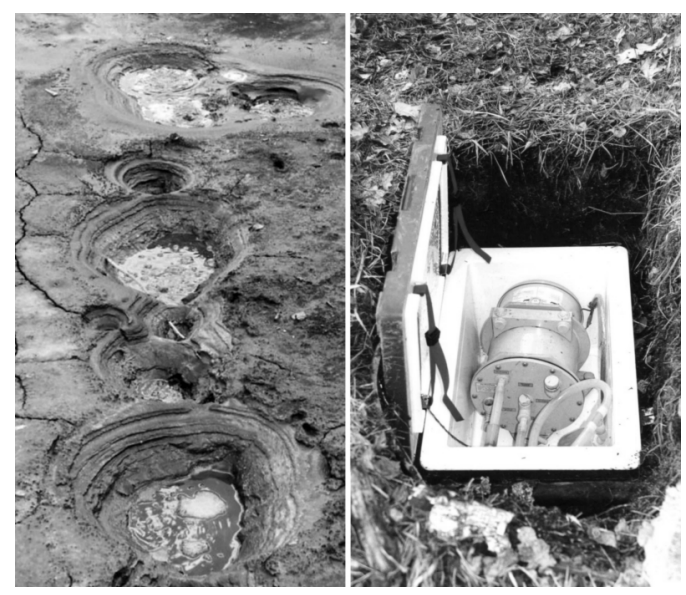

Fig. 4. Mofettes in the Nature Park Soos (CZ) and RITTER gas flow counter at the measuring mofette (right). reserve with an area of $2.2 \mathrm{~km}^{2}$. Moor sedimentation with high mineralisation is the result of a small basin structure with mineral water springs (Brož, 1989). Numerous mofettes are responsible for the high local degassing rates. Contrary to mineral springs, mofettes are dry gas outbursts. In wet periods, they are filled with rain water and near-surface groundwater.

One of the suitable mofettes in the Nature Park Soos has been equipped with a multiparameter station since the late nineties of the last century, but reliable gas flow data have been obtained only after mounting a modern gas meter (RITTER GmbH, Germany; fig. 4). At Bad Brambach, the measuring interval is $10 \mathrm{~min}$ for the gas flow, and $15 \mathrm{~min}$ for groundwater level and air pressure. At Soos, gas flow and mofette water level are recorded with an interval of $10 \mathrm{~min}$.

\section{Results and discussion}

For an identification of seismically induced gas flow anomalies, relatively short periods with high data resolution have to be evaluated

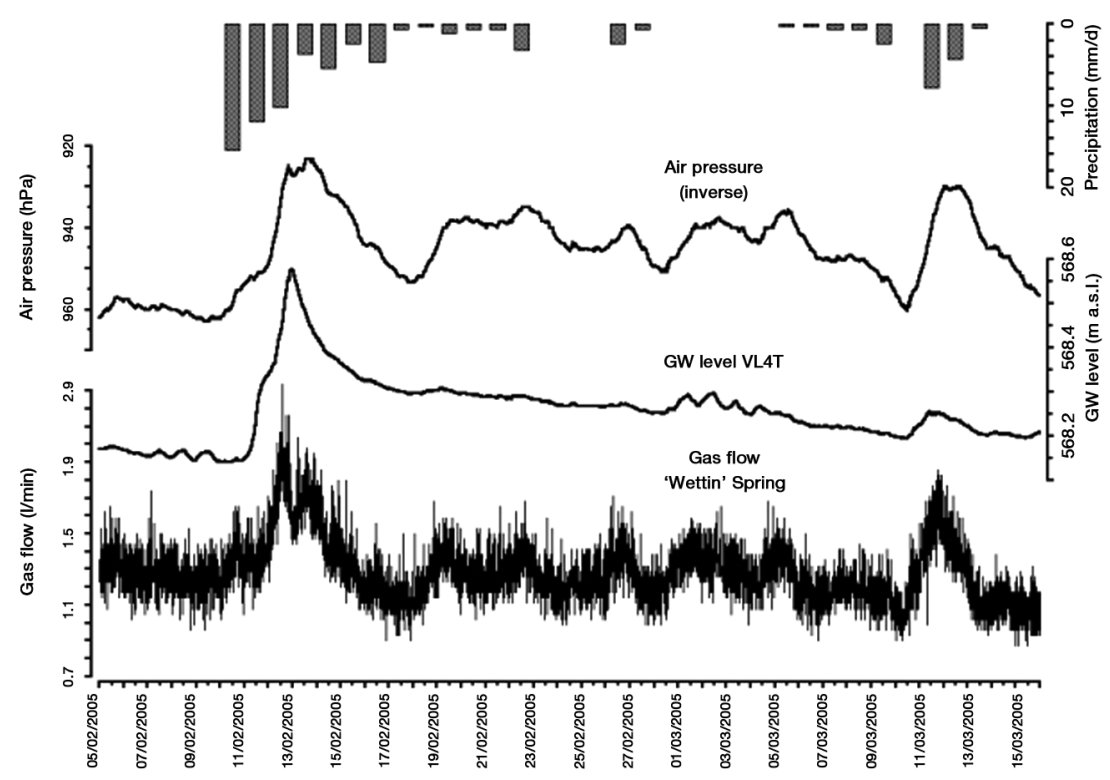

Fig. 5. Example for the dependence of free gas flow at the spring 'Wettinquelle', Bad Brambach on air pressure variations; temporal resolution $10 \mathrm{~min}$ (precipitation $24 \mathrm{~h}$ ). 


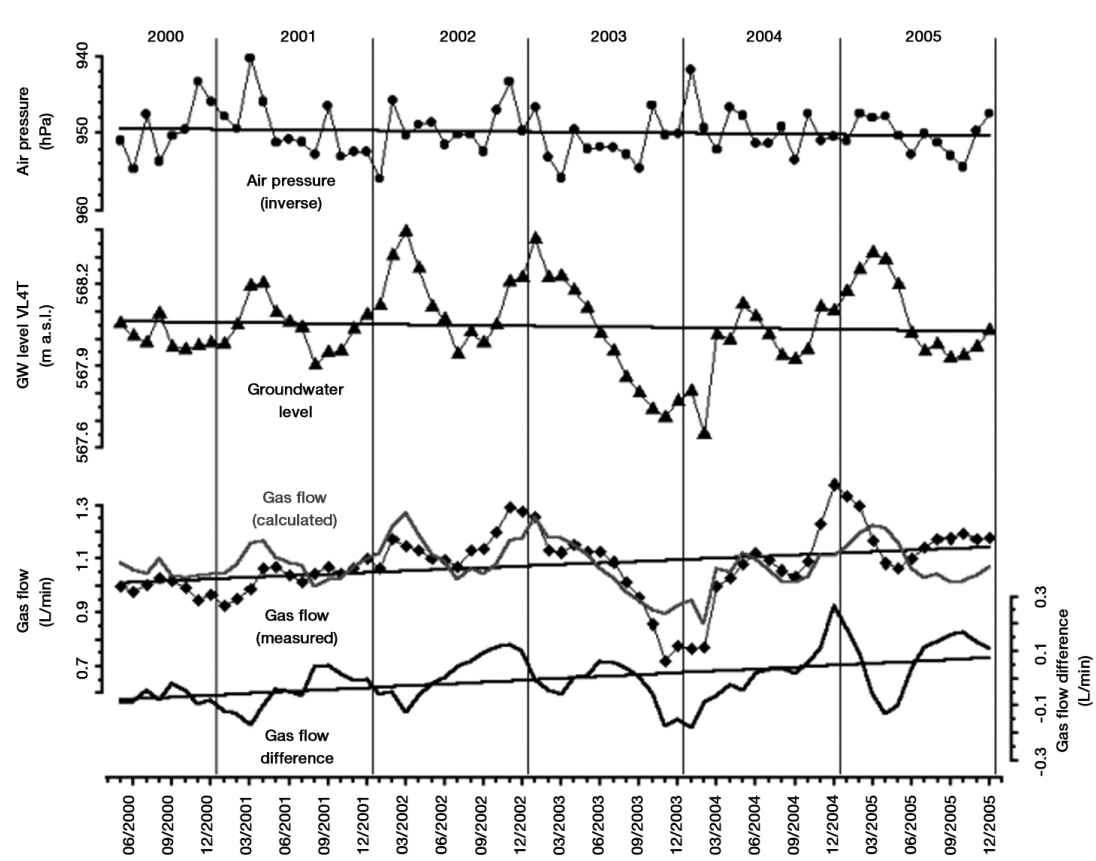

Fig. 6. Monthly averages of air pressure, groundwater level (VL4T) and gas flow of the "Wettinquelle (incl. calculated gas flow and difference curves). Gas flow and flow difference show a temporal upward trend (no trends: air pressure, groundwater level). Note the non-periodical fluctuations of the difference curve (= flow 'excess' and 'deficit', respectively).

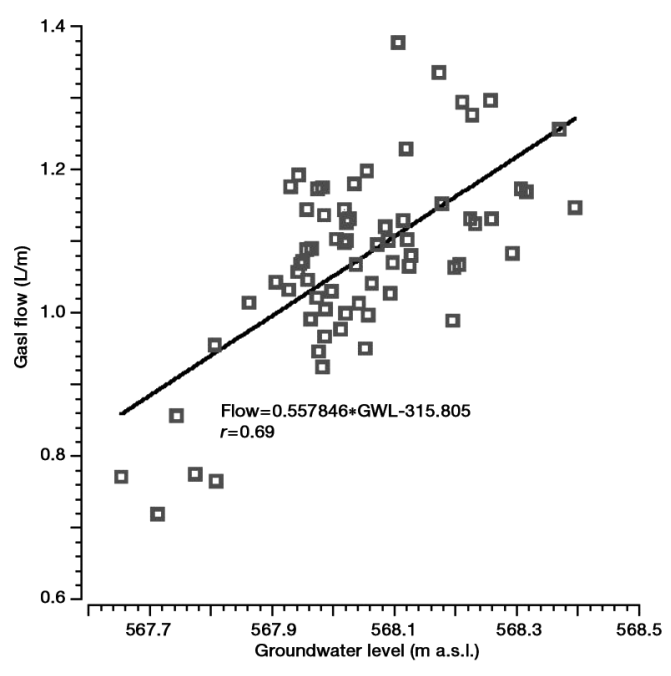

Fig. 7. Correlation between the groundwater level at gauge well VL4T (Cure Park) and gas flow at the 'Wettinquelle' mineral spring, Bad Brambach (monthly averages 05/2000-08/2005). (hours, days to 2-3 weeks). Figure 5 shows the typical short-term dependence of the flow throughout the spring capture of the 'Wettinquelle' on the atmospheric pressure. Here, a correlation between gas flow and groundwater level (hydraulic pressure in the fissured aquifer system) cannot be detected. The significant influence of air pressure on the flow rate of the free gas can easily be separated by a linear regression calculation (Koch et al., 2003).

The approach has to be changed if long-term information on the degassing behaviour is to be obtained. Considering monthly averages, air pressure does not show a long-term trend (fig. 6). However, a significant positive dependence between groundwater level and gas flow can be observed (fig. 7). The reaction time of the aquifer on rainfall or snow melt is relatively short (1-3 days), and the monthly averages of groundwater level directly reflect the according water recharge due to precipitation. Therefore, no precipitation data are taken into account in detail. 
Normally, atmospheric pressure and groundwater level act on the gas flow regime in the same way: a higher exogenous counter pressure against the pressure of the ascending free or the dissolved gas components decreases the gas flow throughout the soil surface. However, the water level of the 'Wettinquelle' represents a permanent and constant sink relatively to the surrounding groundwater level. Air pressure fluctuations influence the whole hydraulic and degassing system equally. But, in case of a groundwater level increase, the permeability of many diffuse gas outlets in the soil around the mineral springs is reduced. Hence, assuming a relatively continuous gas production rate in the depth, a higher gas flux occurs at locations with permanently decreased counter pressure and relatively high fissure permeability, in our case at the hydraulic sink 'Wettinquelle'. This effect may be reinforced at lasting frost periods with snow cover.

To eliminate these groundwater level effects on the gas flow data of the Wettinquelle, a syn-

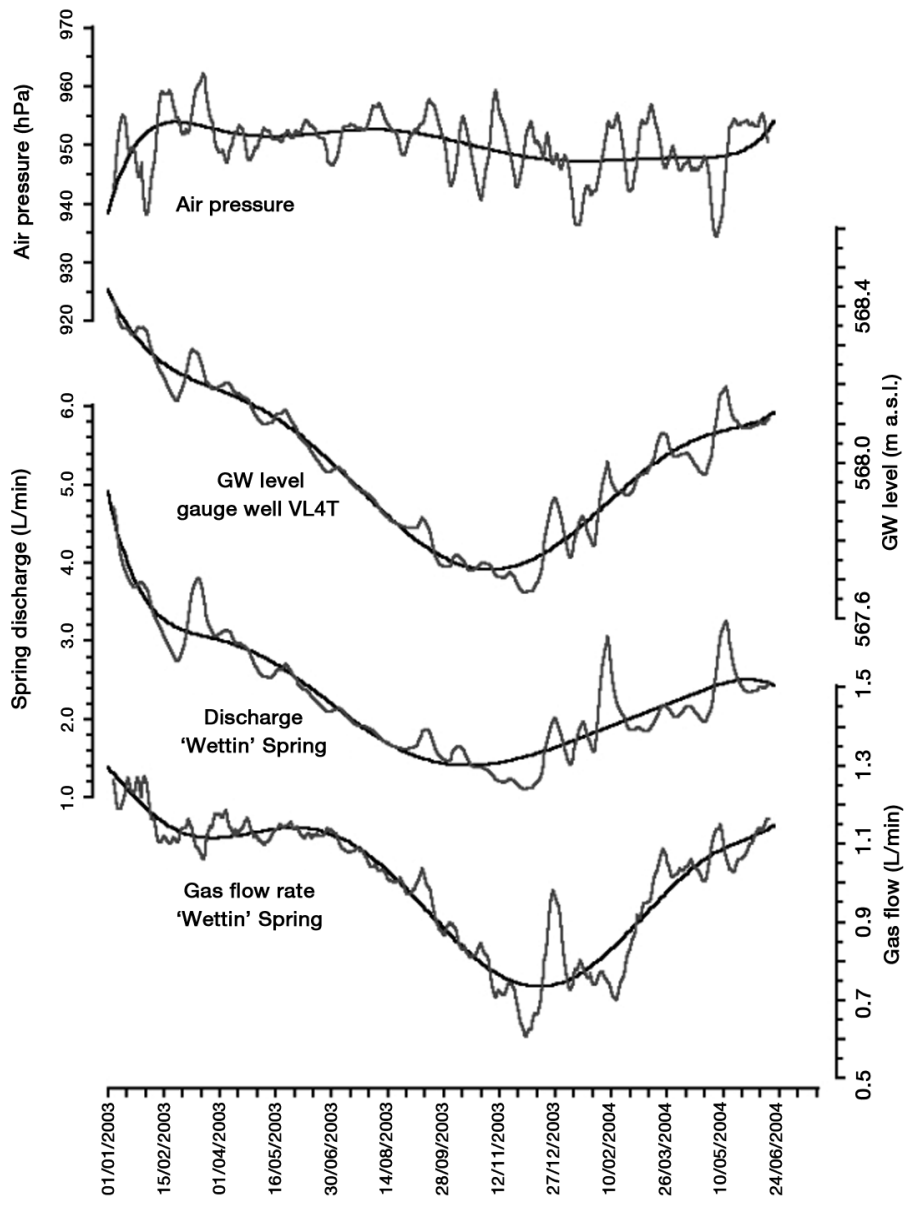

Fig. 8. Relation between air pressure, groundwater level, spring discharge and free gas flow at the spring 'Wettinquelle', Bad Brambach 2003-2004 (polynomially fitted). The dry year 2003 and the additional groundwater lowering at the spring 'Eisenquelle' caused not only a lowering of the surrounding groundwater level but also a decrease of the 'Wettinquelle' spring discharge and gas flow. 


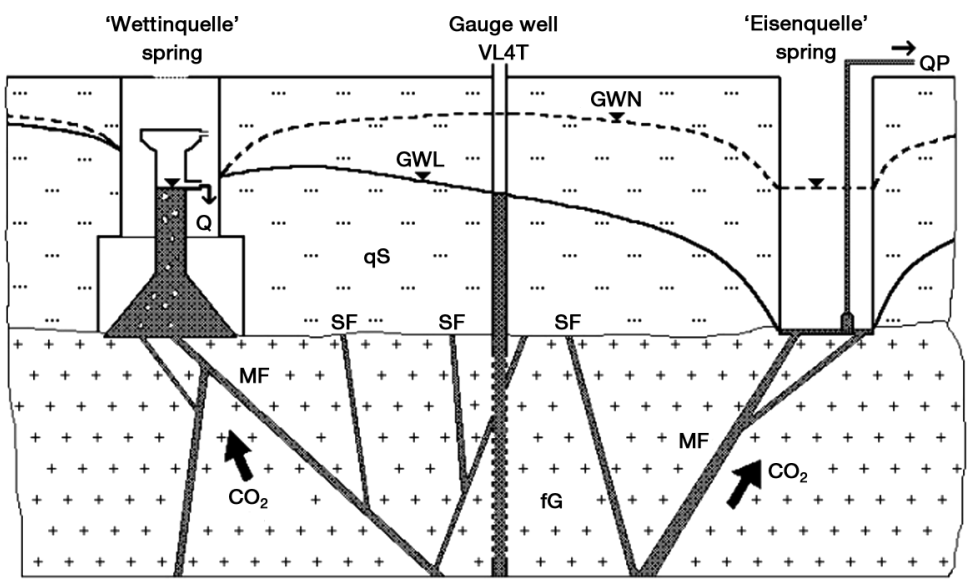

Fig. 9. Effects of decreased groundwater levels on the gas flow regime (schematically): during the groundwater lowering by pumping at the spring 'Eisenquelle' (QP), a remarkable amount of the gas streamed via the Main Fissures (MF) at the 'Eisenquelle' spring bottom and the secondary fissures and pores in the vicinity (SF). The gas flow at the 'Wettinquelle' decreased because of the constant water level in the spring capture; fG - fissured granite; qS - Quaternary sediments; Q - spring discharge; GWN/GWL - natural/lowered groundwater level.

thetic gas flow curve by means of the regression relation in fig. 7 was calculated. This synthetic curve represents the gas flow regime affected solely by deeply originated processes. The difference curve between the measured and synthetic gas flow shows a remarkable 'pulsing' behaviour which, obviously, has no seasonal background (fig. 6). Moreover, a slow gas flow uptrend of about $11 \%$ was observed between 2000 and 2005 .

This long-term gas flow trend was interrupted in the dry year of 2003 because of an extremely low groundwater level whose minimum was about $25 \mathrm{~cm}$ below the minima of the other 5 years. Additionally, that behaviour was superposed by the lowering of the groundwater during the reconstruction of the neighbouring spring 'Eisenquelle' between October 2003 and February 2004 (fig. 8, fig. 9). During that period, a remarkable amount of the gas streamed via the main fissures at the 'Eisenquelle' spring bottom as well as via small fissures and pores in the vicinity because of the reduced hydrostatic counter pressure in the aquifer. Contrary to that, the gas flow at the 'Wettinquelle' decreased because here, the constant, relatively deep adjusted water level was not influenced by the 'Eisenquelle' groundwater lowering. However, the hor- izontal reach of the groundwater depression of $>100$ m caused a significant decrease of the water level in the gauge well VL4T $(60 \mathrm{~m} \mathrm{SW}$ of the 'Eisenquelle') as well as of the water discharge of the 'Wettinquelle' spring (70 m ESE of the 'Eisenquelle).

The curves in fig. 8 (measuring intervals 10 and $15 \mathrm{~min}$ ) have been smoothed and polynomially fitted to eliminate meteorologically induced short-term fluctuations and better illustrate their average behaviour. The decreasing trend of gauge well level and spring discharge up to the end of November 2003 is amplified due to the artificial groundwater lowering between October 14, 2003 and February 24, 2004. Single peaks correspond to precipitation or snow melting events, often coupled to deep air pressure. The latter does not play any role in the seasonal trend of the groundwater regime. The minima of the three lower curves are reached simultaneously. However, the gas flow fitting function suggests a temporal shift of 4 to 6 weeks. This is due to the mathematical overestimation of the negative gas flow gradient which is significantly higher between July and November 2003, compared with that of the hydraulic parameters spring discharge and groundwater level. 
Considering the three Bad Brambach mineral springs equipped with gas flow sensors, a common slight upward trend of the flow rate can be identified (exception: 'Schillerquelle'), in spite of the significant effect of the groundwater lowering during the 'Eisenquelle' reconstruction (fig. 10). In case of the 'Schillerquelle' spring (20 m NNW of the 'Eisenquelle'), the effect of groundwater lowering is large enough to 'efface statistically' the long-term gas flow trend. However, the period during and after the groundwater re-uplift proves the continuation of the gas flow trend at all three mineral springs.

The example of the long-term behaviour of the monthly gas flow average values at a mofette in the Nature Park Soos (see fig. 1) suggests that not only the air pressure but also the mofette water level does not influence the gas flow regime significantly (fig. 11). As at Bad Brambach, the atmospheric pressure and the water level of the measuring mofette do not show a long-term trend. Coincidentally, the gas flow increased about 52\% since the beginning of the advanced flow measurements in 2001. Moreover, a similar 'irregular pulsing' is observed as at the Bad Brambach 'Wettinquelle'. But in case of the 'Wettinquelle', that phenomenon could be detected only after the separation of the influences of groundwater level variations (fig. 6, synthetic gas flow curve). The lack of direct dependence between the monthly averages of mofette water level and gas flow at Soos may be explained by the different hydrogeological background of the mofette field (fig. 12). Contrary to mineral springs, mofettes are dry gas outlets, even if they are filled with rain or nearsurface groundwater during wet periods. They are

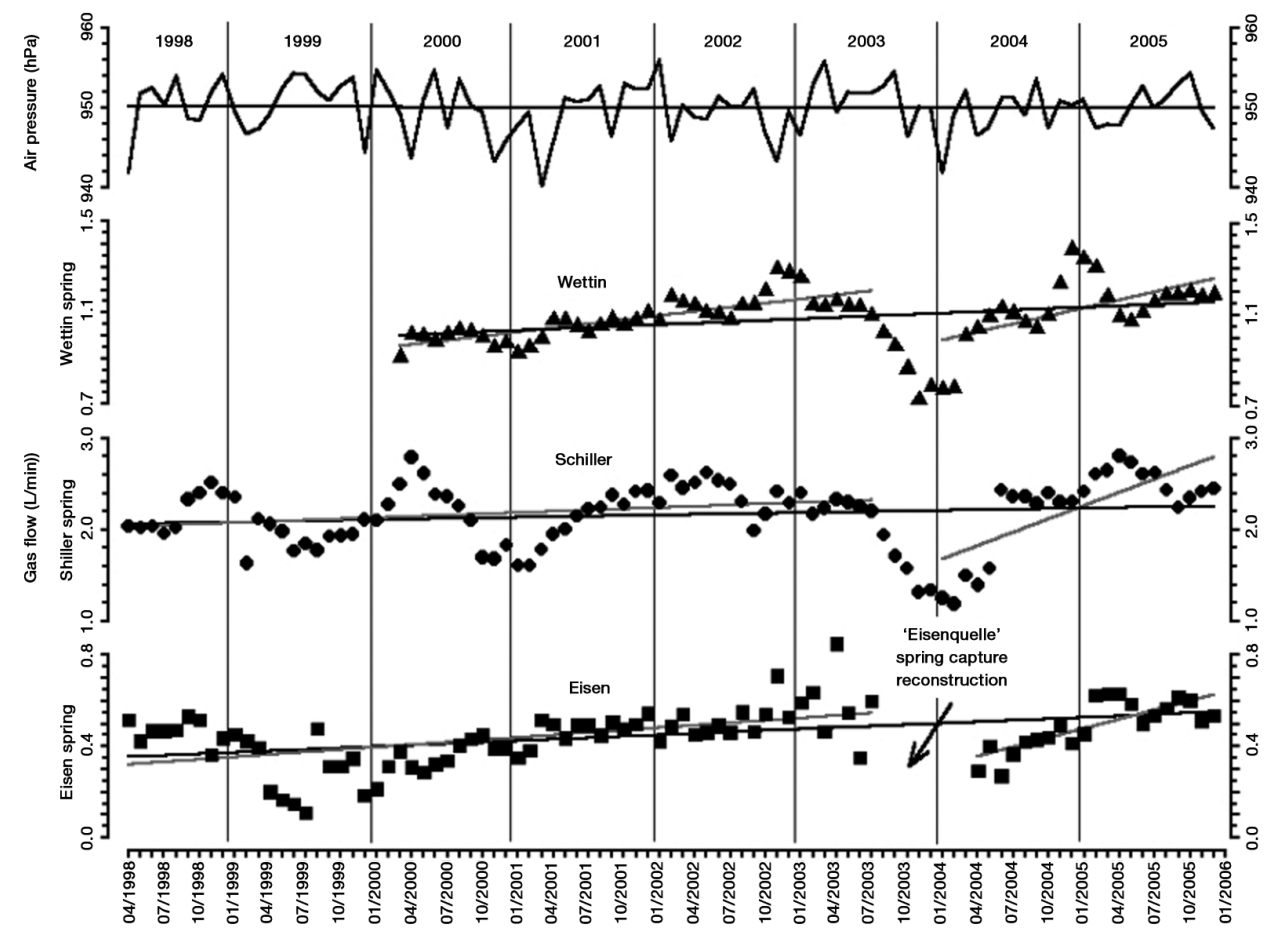

Fig. 10. Since 1998, a common long-term gas flow trend is visible at all three Bad Brambach shallow mineral springs, particularly, considering the periods before and after the groundwater lowering (October 2003-February 2004) separately. A reliable gas flow measurement at the 'Wettinquelle' could be started only in March 2000, after the spring capture reconstruction (data: monthly averages). 


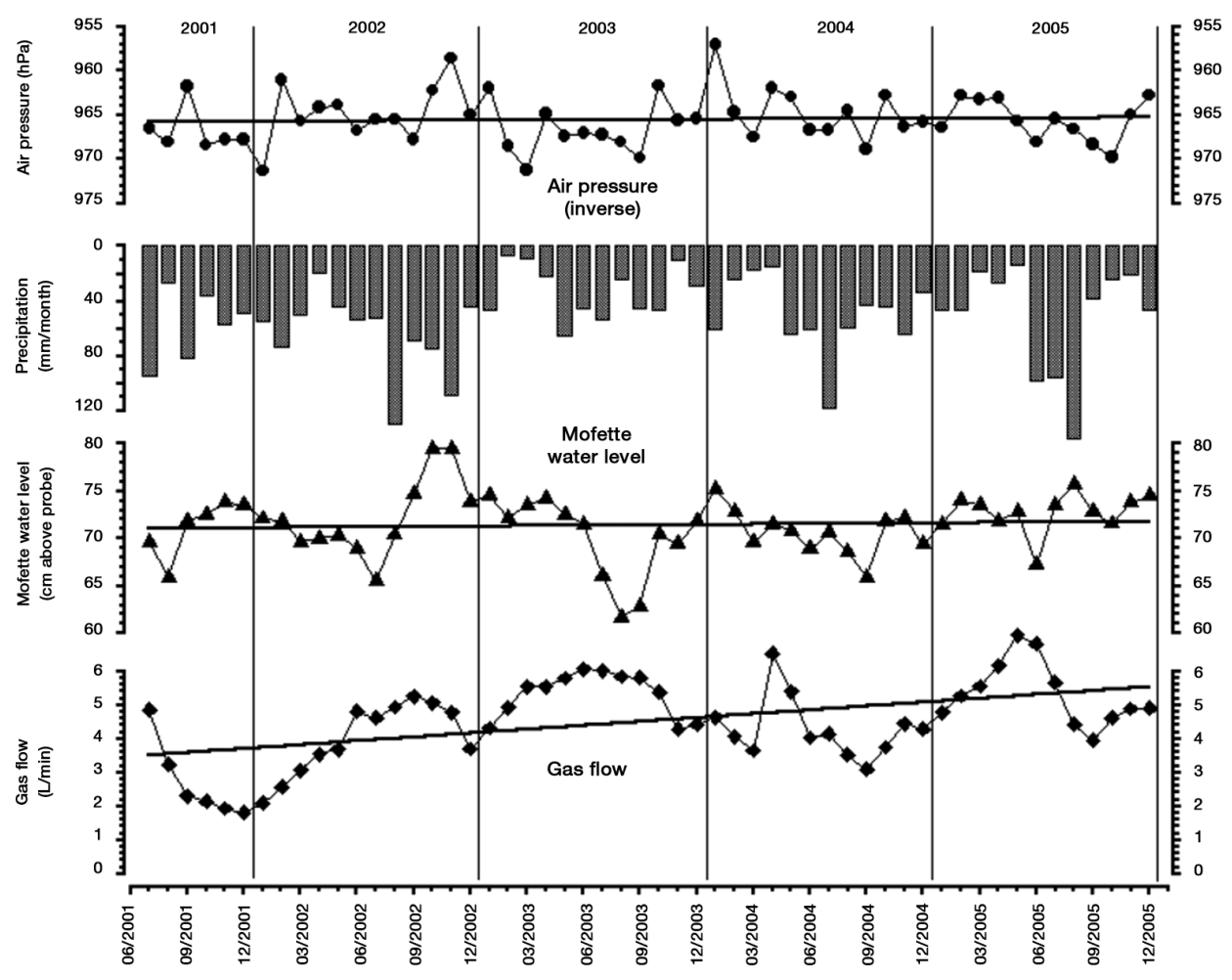

Fig. 11. Long-term gas flow uptrend at a mofette in the Nature Park Soos (CZ). As at Bad Brambach, an irregular pulsing of the gas flow rate is observed also here (data: monthly averages).

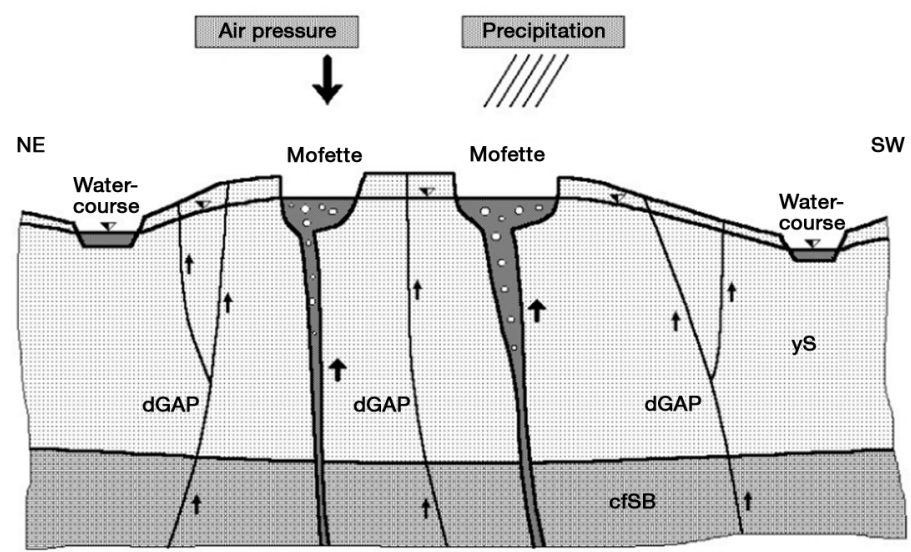

Fig. 12. Mofette field in the Nature Park Soos (schematically): precipitation (water level) and air pressure affect all gas outlets in the uniform way and extent (no permanent hydraulic sinks). Thus, a long-term correction of the mean gas flow values is not necessary; $\boldsymbol{\nabla}$ - water/groundwater level; yS - young sediments; cfSB - consolidated fissured sedimentary basement; dGAP - diffuse gas ascent paths. 
supplied with gas by deep reaching channels with relatively high permeabilities. Any exogenous influences, particularly precipitation (evaporation) and air pressure variations affect the whole mofette system in the same way. Thus, there do not exist permanent hydraulic sinks relatively to the common natural groundwater level. However, in case of short-term gas flow analyses, air pressure and water level variations have to be taken into account.

The Bad Brambach and Soos investigations demonstrate that the observed fluid transport is a very steady process which is controlled by a relatively constant gas emission rate from the crust/upper mantle zone. Short- and mean-term variations in air pressure and groundwater level fluctuations are not able to influence the deep fluid transport process itself, at most, they can affect the gas flow regime for relatively short periods of time.

The similar long-term upward trend both at the Bad Brambach springs and the Soos mofette field marks a long-term behaviour in the degassing regime of the whole region, possibly induced by stress accumulation or hydrothermal processes. These observations are supported by an increasing mantle signature $\left({ }^{3} \mathrm{He} /{ }^{4} \mathrm{He}\right.$ ratio) over more than 12 years as detected by Bräuer et al. (2005a,b and 2007) at gas emission sites in the Cheb Basin which is assumed as an indication for mantle-derived magma intrusions into the lower crust below that area.

Since air pressure and groundwater level are shown not to be long-term exogenous factors acting on the gas flux, it may be concluded that the irregular non-seasonal pulsing of the gas flow rate on the surface is caused by a given periodicity of the fluid transport processes through the crust. Such a mechanism could be based upon geotectonically induced varying hydrofracturing processes possibly due to slight pore pressure perturbations (Gudmundsson et al., 2003; Shapiro et al., 2006).

\section{Conclusions}

The free gas flow throughout springs and mofettes is an important indicator for seismohydrological effects. It is influenced mainly by two non-seismic parameters: air pressure and groundwater level.

The air pressure effect has to be taken into account for the analysis of short periods (hours, days to 2-3 weeks). Considering longer periods, the groundwater level becomes the dominating factor. Its influence on the gas flow rate depends on the type of the gas emission site: permanent hydraulic sinks (managed springs, wells with lowered water level), or gas outlets representing directly the local water/groundwater level (mofettes, non-managed open springs, creeks, lakes etc.).

The highest groundwater level-induced gas flow fluctuations should be expected at springs with permanently decreased water level (e.g. 'Wettinquelle', Bad Brambach).

Accounting for all influencing effects, a slight upward trend of the gas flow can be detected for the last 5 years at the Bad Brambach measuring site, and a stronger one at a mofette in Soos (CZ). Moreover, the observed ${ }^{3} \mathrm{He} /{ }^{4} \mathrm{He}$ mantle ratio increase in gases at mofettes in NW Bohemia indicates a higher degassing activity of the magma body below the Cheb Basin (Bräuer et al., 2005a,b, 2007).

The detected non-seasonal pulsing of the gas flow rate is assumed to be caused by a periodicity of the fluid transport through the crust which could be based upon varying geotectonically induced hydrofracturing processes possibly due to slight pore pressure perturbations (Gudmundsson et al., 2003; Shapiro et al., 2006).

\section{Acknowledgements}

The authors thank the Cure Director of the Saxon State Spas Bad Brambach-Bad Elster, Dr. Christian Kirchner, for his steady support of their research work for many years, Karel Brož, Nature Park Soos (CZ), for giving the opportunity to operate measuring stations at this interesting location, as well as both reviewers for valuable hints and remarks.

\section{REFERENCES}

BrÄUer, K., H. KÄMPf, G. Strauch and S.M. Weise (2003): Isotopic evidence $\left({ }^{3} \mathrm{He} /{ }^{4} \mathrm{He},{ }^{13} \mathrm{C}_{\mathrm{CO} 2}\right)$ of fluid- 
triggered intraplate seismicity, J. Geophys. Res., 108 (B2), 2070, doi: 10.1029/2002JB002077.

Bräuer, K., H. Kämpf, S. Niedermann and G. Strauch (2005a): Evidence for ascending upper mantle-derived melt beneath the Cheb Basin, Central Europe, Geophys. Res. Lett., 32, L08303, doi: 10.1029/2004GL022205.

BRÄUER, K., H. KÄMPF, E. FABER, U. KOCH, H.-M. NITZSCHE and G. STRAUCH (2005b): Seismically triggered microbial methane production relating to the Vogtland-NW Bohemia earthquake swarm period 2000, Central Europe, Geochem. J., 39, 441-450.

BrÄUER, K., H. KämpF, U. Koch, S. NiedermanN and G. STRAUCH (2007): Seismically-induced changes of the fluid signature detected by a multi-isotope approach $\left(\mathrm{He}, \mathrm{CO}_{2}, \mathrm{CH}_{4}, \mathrm{~N}_{2}\right)$ at the «Wettinquelle», Bad Brambach (Central Europe), J. Geophys. Res., 112, B043047, doi: 10.1029/2006JB004404.

Brož, K. (1989): Státní Přírodní Rezervace Soos, Guidebook Muzeum Františkovy Lázně, pp. 22.

Gudmundsson, A., O. GJesdal, S.L. BRENNER and I. FJeldSKAAR (2003): Effects of linking up discontinuities on fracture growth and groundwater transport, Hydrogeol. J., 11 (84-99), doi: 10.1007/s10040-002-0238-0.

HAINZL, S. and T. FISCHER (2002): Indications of a succesively triggered rupture growth underlying the 2000 earthquake swarm in Vogtland/NW Bohemia, J. Geophys. Res., 107 (B12), 2338, doi: 10.1029/2002JB001865.

Heinicke, J. and U. Koch (2000): Slug flow - A possible explanation for hydrogeochemical earthquake precursors at Bad Brambach, Germany, Pure Appl. Geophys., 157 (10), 1621-1641.

Heinicke, J., U. Koch and G. MARTinelli (1995): $\mathrm{CO}_{2}$ and Radon measurements in the Vogtland area (Germany) A contribution to earthquake prediction research, Geophys. Res. Lett., 22, 771-774.

HorÁleK, J., F. HAMPL, A. BouŠKovÁ and T. FISCHER (1996): Seismic regime of the West Bohemian earthquake swarm region: preliminary results, Studia Geophys. Geod., 40, 398-412.

HoráleK, J., J. ŠilenÝ, T. Fischer, A. Slancová and A. BouŠKovÁ (2000): Scenario of the January 1997 West Bohemia earthquake swarm, Studia Geophys. Geod., 44, 491-521.

Koch, U. and J. HeInICKE (1996): Earthquake prediction research by radiometric-geochemical methods in the Vogtland-NW Bohemian region: new results and aspects, in Proceedings of the XXV General Assembly European Seismol. Commission, Reykjavik (Icelandic Meteorological Office, Reykjavík), 241-246.
Koch, U. and J. HeInICKE (1999): The precursor effects in the mineral spring 'Radonquelle', Bad Brambach prior to the January 14-19, 1997 earthquake swarm near Nový Kostel (NW Bohemia), Nuovo Cimento, 22 (3-4), 431-436.

Koch, U., J. Heinicke and M. Vossberg (2003): Hydrogeological effects of the latest Vogtland-NW Bohemian swarmquake period (August to December 2000), J. Geodyn., 35 (1-2), 107-123.

McGee, K.A., T.M. Gerlach, R. Kessler and M.P. DOUKAS (2000): Geochemical evidence for a magmatic $\mathrm{CO}_{2}$ degassing event at Mammoth Mountain, California, September-December 1997, J. Geophys. Res., 105 (B4), 8447-8456.

Pinault, J.-L. and J.-C. BAubron (1997): Signal processing of diurnal and semidiurnal variations in radon and atmospheric pressure: a new tool for accurate in situ measurement of soil gas velocity, pressure gradient, and tortuosity, J. Geophys. Res., 102 (B8), 18101-18120.

Reddy, D.V., B.S. Shukhija, P. Nagabhushanam and D. KuMAR (2004): A clear case of radon anomaly associated with a micro-earthquake event in a Stable Continental Region, Geophys. Res. Lett., 31, L10609, doi: 10.1029/2004GL019971.

Rogie, J.D., D.M. Kerrick, M.L. Sorey, G. Chiodini and D.L. Galloway (2001): Dynamics of carbon dioxide emission at Mammoth Mountain, California, Earth Planet. Sci. Lett., 188, 535-541.

Shapiro, S.A., J. Kummerow, C. Dinske, G. Asch, E. RoTHERT, J. ERZINGER, H.-J. KÜMPEL and R. KIND (2006): Fluid induced seismicity guided by a continental fault: Injection experiment of 2004/2005 at the German Deep Drilling Site (KTB), Geophys. Res. Lett., 33, L01309, doi: 10.1029/2005GL024659.

ŠPIČÁK, A. and J. HoRÁLEK (2001): Possible role of fluids in the process of earthquake swarm generation in the West Bohemia/Vogtland seismoactive region, Tectonophysics, 336 (1-4), 151-161.

Weinlich, F.H., K. Bräuer, H. Kämpf, G. Strauch, J. TESAfi and S.M. WeISE (1999): An active subcontinental mantle volatile system in the Western Eger Rift, Central Europe: gas flux, isotopic ( $\mathrm{He}, \mathrm{C}$, and $\mathrm{N}$ ) and compositional fingerprints, Geochim. Cosmochim. Acta, 63, 3653-3671.

Weise, S.M., K. BräUer, H. KämPF, G. Strauch and U. KосH (2001): Transport of mantle volatiles through the crust traced by seismically released fluids: a natural experiment in the earthquake swarm area Vogtland-NWBohemia, Central Europe, Tectonophysics, 336, 137-150. 